\title{
LOS ESTUDIOS FAUNISTICOS Y DE BIOPROSPECCIÓN EN LA EDUCACIÓN \\ DE LOS COLOMBIANOS
}

Rodrigo Torres Núñez y Martha Jeaneth García Sarmiento*

Al final sólo conservaremos, aquello que amemos, sólo amaremos aquello que comprendamos, sólo comprenderemos aquello que se nos enseñe".

Baba Dioum

\begin{abstract}
Colombia is a tropical country with one of the biggest biological diversity of the world. But much of this biodiversity is being irreversibly lost through extinction caused by the destruction of natural habitats. The social and political problems in the area increase the problem. The implication and scientific, educational, social and economic impact of the faunistic surveys are commented.
\end{abstract}

\section{PALABRAS CLAVES}

Colombia, biodiversidad, faunística, conservación, educación, investigación.

\section{INTRODUCCIÓN}

Dentro del tema de ja investigación de la diversidad zoológica y ubicándonos dentro de una estrategia general, aplicable a los esfuerzos específicos que podrían llegar a configurarla podemos afirmar que el conocimiento actual de la fauna Colombiana, e incluso neotropical, en relación con la muy vasta y peculiar diversidad ecológica y biológica es supremamente limitado Colombia no obstante presentar una de las mayores biodiversidades del mundo (número de especies diferentes por kilómetro cuadrado de territorio terrestre continental), posee relativamente muy pocos estudios publicados alrededor de las especies que habitan dentro de su territorio, mucho más si de invertebrados se trata. Como si esto fuera poco, se suma otra condición muy aguda, de gran trascendencia y común a casi todos los países tropicales: la pérdida vertiginosa de dicha Biodiversidad pudiendo llegar ésta a proporciones catastróficas durante los próximos 15 años. Vale anotar aquí, que no se trata sólo de aves y mamíferos, sino también de formas de vida menores, tales como musgos, insectos, peces y otras especies que aunque menos ostensibles para el observador común, constituyen la mayor parte de

\footnotetext{
* Profesores Departamento ce Biología Museo de Historia Natural, Universidad Pedagógica Nacional Bogotá. D.C.
} 
la base primordial del complejo de ecosistemas. Los invertebrados y entre ellos los artrópodos poseen un inmenso significado ecológico y la pérdida de sus especies constituye sin duda una parte valiosa de la diversidad.

Un cálculo conservador acerca de la extinción global es de 1.000 especies anuales, debida principalmente a la destrucción por el hombre de bosques y otros hábitats básicos, tales como ríos, lagunas y páramos de los trópicos. Se presume que en la década de los 90 la cifra llegará a 10.000 especies al año (una especie por hora), siendo posible que en los próximos 30 años desaparezcan un millón de especies.

En esta inmensa y amenazada diversidad, sin precedentes en la historia de la vida sobre el planeta, la ya lejana labor de Linneo de reconocer y en lo posible describir el mundo viviente permanece obligadamente como parte urgente de la ciencia moderna más si con razón deducimos que muchas de las especies actuales, habrán desaparecido irremediablemente antes de siquiera haber recibido un nombre científico, y mucho menos haber reconocido un mínimo de sus casi siempre interesantes y valiosas potencialidades entre las que se cuentan no solo su valor intrínseco y científico, sino también su gran y a menudo insospechado valor instrumental, representado -para solo citar lo conocido- en aspectos tales como la educación, la genética, la farmacología, la inmunología, la citología, la nutrición, la agricultura y muchas otras.

Por otra parte muchos biólogos y antropólogos comparten la idea de que la utilización sistemática y racional de los recursos naturales es la clase de investigación que más fácilmente se justifica en las naciones en desarrollo. Así también es el tipo de contribución que con menor dificultad puede costearse. Muy probablemente los resultados científicos, autorales, educativos y de otra índole que se obtengan recibirán reconocimiento mundial, pudiendo incluso ser fuente de orgullo y realización tanto institucional como nacional.

\section{ESTUDIOS FAUNISTICOS Y DE BIOPROSPECCION A NIVEL NACIONAL}

¿Para que nacer el gasto y esfuerzo de llevar a caco un inventario de la biodiversidad Nacional en un país tropical como Colombia? ¿Para qué sirve una lista de especies? ¿Para qué nos importa saber cuales de éstas están en la Lista o incluso cuantas habitan en el país? No se trata de cuantas especies están en la lista, cada país tropical que todavía posee áreas silvestres tiene por supuesto, cientos de miles de especies. Estas podrían llegar a extinguirse o quizás no La importancia de saber si éstas habitan en el país es directamente proporcional a que tanto sabemos acerca de ellas más que debido a su presencia en la lista La lista de especies es el subproducto de un inventario -no el objetivo del inventario. Es el índice en el catálogo de compras". Es una de las muchas formas de señalar la existencia y paradero del conocimiento de qué es lo que hay en el invernadero, la bodega" o el "inventario de la corporación".

Por lo anterior, cuando un país tropical realiza estudios faunísticos y de bioprospección, no esta llevando a cabo una lista de sus especies per se Está elaborando un edificio de conocimientos y un sistema de referencia científica y por su puesto educativa.

Entonces. ¿qué son los estudios faunísticos y de bioprospección? En su forma más simple se trata de especimenes (o de sus genes o constituyentes químicos) taxonómicamente claros acompañados de una información o base de datos que indique cuando menos un lugar en el país donde dichos especimenes puede ser encontrados. En 
la medida que la biodiversidad de un país es investigada y utilizada por todos los integrantes de la sociedad, el inventario podrá tornarse más rico en información sobre la distribución geográfica de las especies, microhábitat e historia natural (incluyendo referencias sobre la existencia de literatura) y llegará a hacerse sistemática y taxonómicamente más claro, en la medida que se estudie la biodiversidad del continente y ésta a su vez pueda ser utilizada. Los inventarios de otros países, nuevas monografías, nueva información biológica, cladistica, etc. podrían ser el mecanismo para depurarlo

¿Cuál es la alternativa a los estudios faunísticos y de bioprospección? En la medida que cada especie llega a ser de interés o motivo de preocupación para alguien en la sociedad. Es en ese momento en que al parecer el trabajo taxonómico y ecológico preliminar resultan necesarios para que la ausencia de una comprensión taxonómica o ecológica no nos impida la acción. Debemos ser francos, buena parte de la interacción entre las sociedades extratropicales y la biodiversidad ha estado basada en este principio. Pero una cosa es cuando el manejo de la biodiversidad hace relación a una sola plaga de un cultivo y a dos agentes para el control biológico, y otra muy diferente es cuando la biodiversidad está representada cuando menos por 3'000.000 especies de insectos a ser muestreadas en lo relacionado con su química defensiva, o de quizás 20-30 millones de especies de insectos que esperan a ser descritos y de los cuales nuestra geografía alberga más del $90 \%$. Y si el destino de un país tropical es el de un agropaisaje monomórfico, como por ejemplo China, Haití, Holanda y El Salvador en la actualidad, la metodología del no inventario podría ser la adecuada (especialmente si fallamos en evitar que los países tropicales vean algo más interesante e inspirador para su pueblo que los campos de caña de azúcar, los invernaderos de pompones y astromelias los antropodesiertos o las cada vez mas grandes extensiones de coca y amapola).

\section{IMPLICACIONES E IMPACTO EDUCATIVO, SOCIAL Y ECONÓMICO}

Cada vez mas conscientes del valor intrínseco de la diversidad biológica, así como de sus réditos ecológicos, genéticos y socioeconómicos resulta indiscutible para la mayoría de las naciones civilizadas, que junto con estos valores, la Biodiversidad posee una gran trascendencia en relación con lo educativo, cultural, recreativo y estético.

La conservación de la biota en sus millones de termas no es solo un asunto de científicos La vida de todos los humanos se puede enriquecer cultural, estética y anímicamente a partir del solo contacto educado con otros organismos y sus ambientes, hecho un poco ajeno a nuestra experiencia, debido en buena parte al marcado corte antropocéntrico de nuestra educación formal, como también y quizás todavía más importante, a la falta lógica de estrategias educativas acordes con tan necesario acercamiento.

Con respecto a lo anterior, el afamado ecólogo y conservacionista Paul Ehrlich, afirma que una humanidad consciente de los imperativos ecológicos, encaminándose hacia un mundo viable y pacifico, debe extender su interés moral y ético, más allá de los seres humanos y las mascotas de la familia, para abrazar el sistema completo de la biosfera. En este orden de ideas, comenzar a conocer y a divulgar las especies del entorno, podría ser uno de los primeros pasos hacia la elaboración de unos elementos que incidan positivamente en la creación de una educación que nos haga cada vez mas conocedores de a realidad de ja tierra y que por depender enteramente de ella nos veamos obligados a 
escuchar sus mensajes con mayor atención de lo que la actual educación nos permite percibir.

Ideas y actividades como las que aquí se proponen están encaminadas al fortalecimiento de la base de conocimientos sobre la fauna del país. La información obtenida no solo está dirigida a científicos y especialistas, también es de gran utilidad como fuente de información básica para los distintos esfuerzos divulgativos y sensibilizadores, los cuales pueden entre otros ir desde la gestión de libros y manuales dirigidos al gran público hasta programas de televisión, videos, multimedia y películas producidas con fines educativos y recreativos.

De manera creciente materiales vernáculos sobre historia natural y seres vivos están siendo incorporados a los currícula y otros recursos escolares y universitarios. Aquí es importante destacar que éste tipo de materiales además de estar inspirados y necesariamente apoyados en información básica sobre la fauna local, fomentan en lugar de una valoración consumista, una apreciación escénica de la naturaleza.

En síntesis el valor real de éste tipo de investigaciones en lo que atañe a lo educativo, radica en el incremento de nuestro conocimiento, que además de reforzar nuestras capacidades docentes y didácticas nos proporcionan no solo un mejor conocimiento acerca del ambiente local, sino un enriquecimiento contagioso de la sensibilidad y experiencia humana.

De otra parte, y ya en relación con el impacto económico de este tipo de estudios y su relación con el reconocimiento y conservación de la diversidad biológica, el aspecto pecuniario tiene que ver en la actualidad con los denominados derechos de biopropiedad. En estos se considera, al menos dentro del sistema capitalista, que los recursos genéticos-silvestres y culturales, son factor de producción esencial para la biotecnología, por lo que los países que los poseen y conocen adecuadamente tienen derecho a beneficiarse en términos económicos, comerciales y científicos de los progresos tecnológicos y de los productos obtenidos En este contexto, serán los estados soberanos los que determinarán entonces el acceso a los recursos de acuerdo con lo estipulado en las legislaciones nacionales.

Como puede deducirse fácilmente, el ejercicio de dichos derechos resulta imposible, a menos que se lleven adelante una diversidad de tareas de gran urgencia, entre las que se incluye el reconocimiento y documentación de la Biodiversidad local -no es posible ejercer derechos y prebendas económicas sobre algo que aunque sentimos, desconocemos El estado y sus instituciones requieren con urgencia la ejecución de inventarios y evaluaciones regulares que le permitan estudiar, controlar y utilizar sustentablemente los recursos biológicos y genéticos. Para lograr este impacto económico las actividades de investigación además de ser ocales deben abrirse al escrutinio público y sus resultados disponer de amplia divulgación.

Los países tropicales necesitan taxónomos y similares con diferente nivel y enfoque para unirse a las fuerzas de trabajo científico y docente que están creando conocimiento y divulgación sobre la biodiversidad, colocándola dentro del medio intelectual y económico de las regiones tropicales. El alfabeto, gramática y sintaxis que los taxónomos nos ofrecen constituye una gran literatura biológica que incluso fue practicada por nuestros ancestros quienes en su tiempo poseían una elegante y efectiva comprensión de las tierras salvajes en que evolucionaron y vivieron. Los taxónomos contemporáneos quizás no son 
conscientes de su fortuna al poder leer la naturaleza salvaje. Cada insecto es el titulo de un libro. Cada árbol es una palabra en un párrafo, cada ave es un párrafo en un capitulo. Los hombres del trópico de nuevo y con urgencia debemos aprender a leer y a contagiar la naturaleza del trópico. Esta debe pasar de ser el verde cotidiano y difuso actual a ser derribado sobre el lodo de la irracionalidad y la violencia, a un torrente de investigadores, libros y docentes.

\section{BIBLIOGRAFIA}

BROWN, Jr K. S. Conservation of neotropical environments: Insects as indicators, In COLLINS, N. M. and THOMAS, J. A. (Eds). The Conservation of insects and their habitats. London. Academic Press, pp. 449-504. CTE. 158, 187, 1991.

CHADWICK, D. Dead or Alive. The Endangered Species Act. National Geographic. 187(3): 2-41, 1995.

EHRLICH, P. R.; EHRLICH, A. H. Extinción: Causas y consecuencias de la desaparición de especies. Argentina, Editorial Fraterna. 1984.

HAIR. J. D. and POMERANTZ. G. A. The educational value of wildlife. In DECKER, D. J. and GOFF (Eds), Valuing Wildlife: Economic and Social Perspectives, pp. 197-207. Westview Press, Boulder, CO. U.S.A. 1987

HEAT, J. and PERRING, F. Imperial Chemical Industries Limited. North Block, Thames House, Millbauk, London. SW1P4Q6. Endeavour Vol. 34. 103-108, 1975.

JANZEN, D.H. What Does Tropical Society Want from the Taxonomist? In La Salle and Gauld, ID. (Eds.). Hymenoptera and Biodiversity. CAB International, Wallingford, Oxon, UK.1993

PRIMACK, R. 6. Essentials of Conservation Biology. Sinauer Associates, Inc. Souderland, Mass. 01375, U.S.A.

SOULE, M. E. (Ed). Conservation biology: The science of scarcity and diversity. Sunderland, Ma. 1986.

UICN - PNUMA - WWF. Estrategia Mundial para la Conservación, 1980.

WILSON. E. O. Biofilia. Fondo de Cultura Económica. México D. F. 1989. 